\title{
Frequency and severity of drought in the Lake Victoria region (Kenya) and its effects on food security
}

\author{
Joseph L. Awange ${ }^{1, *}$, June Aluoch ${ }^{2}$, Laban A. Ogallo ${ }^{3}$, Monica Omulo ${ }^{2}$, Philip Omondi ${ }^{3}$ \\ ${ }^{1}$ Department of Spatial Sciences, Division of Resources and Environment, Curtin University of Technology, GPO Box U1987, \\ Perth, Western Australia 6845, Australia \\ ${ }^{2}$ Department of Environment Sciences, Maseno University, PO Box 333, Maseno, Kenya \\ ${ }^{3}$ IGAD (Intergovernmental Authority on Development) Climate Prediction and Applications Centre (ICPAC), \\ PO Box 10304 - 00100, Nairobi, Kenya
}

\begin{abstract}
Using monthly and seasonal precipitation data for the period 1961-1999, we established drought frequency and severity in relation to food security in the Lake Victoria region in Kenya. We used percentiles together with time series analysis for a $40 \mathrm{yr}$ period, with the lower $25 \%$ of the quartile designated as the threshold values that indicate drought years. We then used percentiles and Drought Severity Index (DSI) to ascertain the physical conditions and severity of the drought years. The 1980s and 1990s were drier decades (the 1980s had more drought events than any other decade considered in this study), with lower negative anomalies in comparison to the 1960s and 1970s, and the number of drought events and their severity have been increasing in recent years (especially during the 1990s). In general, drought affects the crop planting seasons of March to May (MAM) and September to November (SON), and leads to increased food imports in the years following the drought. If the present trends persist, the Lake Victoria region will face not only more severe drought events, but also significant reductions in food security.
\end{abstract}

KEY WORDS: Lake Victoria $\cdot$ Food Security $\cdot$ Climate $\cdot$ Drought $\cdot$ Environment

\section{INTRODUCTION}

Lake Victoria is a riparian resource shared by 3 East African countries: Kenya, Uganda and Tanzania. It serves as a source of water for irrigation, transport, domestic and livestock uses and a source of livelihood for about 30 million people living around the lake. Its fish (tilapia and Nile perch) are exported the world over. Its role as an indicator of environmental and climate change on long term scales has been documented in Nicholson (1998). The vital role of this lake and its surroundings as a source of food has been documented e.g. in Awange \& Ong'ang'a (2006).

The lake and its environment is under threat from environmental pollution and more recently from declining water levels. Drought is thought to have contributed to this decline, which has had a number of social and economic effects. In Uganda, the situation has been severe enough to affect power production, with resulting economic losses (Otieno \& Awange 2006). Water intakes supplying major towns and cities have had to be extended deep into the lake, thus causing further financial burden to the already strained municipalities. Some wetlands that were breeding places for fish are drying up, for example Usoma in Kenya. All these factors (combined with other existing factors) contribute to a worsening food situation in the region. Food insecurity (i.e. a lack of basic food to provide enough energy for day to day activity) in this region could lead to a catastrophe (Skees 2000), since many of the local communities living near Lake Victoria are among the poorest (see e.g. Aseto et al. 2003, Awange \& Ong'ang'a 2006) and most food insecure in the region, due to high population densities (Ehrlich et al. 1993, Swaminathan 2001), widespread poverty, recurrent droughts, crop failures, high mortality rates 
(from tuberculosis, malaria, and HIV/AIDS), and environmental degradation (contamination, pollution, land/ forest degradation, biodiversity degradation, introduction of exotic species; Awange \& Ong'ang'a 2006). Shipton (1990) reviewed the famine and food shortage situation in Africa and focused specifically on those who suffer and the action they take-information which may be vital to the lake region.

Food security is dependent on social, economic as well as climatic factors. Climatic extremes, particularly droughts and floods, affect the state of food security in Africa (Kodamura 1994, Scoones et al. 1996). Climatic extremes are normal climatic occurrences and their impacts on society vary with respect to vulnerability and the success or failure of coping mechanisms at both the household and national level. Absence of adaptation measures to climate variability results in negative impacts on food security, health, and ultimately, life. An example is the 1999-2001 drought that affected most parts of Kenya, including some areas that normally receive high rainfall. At its peak, 4.5 million people in Kenya lost their livelihoods and ability to cope, and were subsequently entirely dependent on relief food provided jointly by the government and donors (DMCN 2002). Adger et al. (2003) discussed adaptation to climate change related phenomena in developing countries while Barrett (2002) described food assistance programs. The impacts of such extremes (in the context of climate change) on Lake Victoria Basin (LVB) has been assessed in Phoon et al. (2004).

In the LVB, floods are more frequent than drought and have had adverse impacts. The climate within the region is highly variable with a higher natural susceptibility to frequent climate extremes than neighbouring regions. In the past, the majority of interventions in the region have been in flood management. However, drought, which is a slow and progressive extreme climatic event, has until recently been the least anticipated extreme in this region filled with wetlands. As a result, its impacts are more adverse than those of floods because of the inadequacy of existing coping mechanisms.

Although drought is a natural, recurring phenomenon which cannot be controlled (Garcia \& Escudero 1982, Glantz 1987, Akong'a \& Downing 1988, Downing et al. 1989), prediction of its frequency, severity and probability is essential for farmers in that it helps in planning and management. In the absence of such information, food security is threatened. Lack of such information in Uganda, for instance, exacerbated the impact of drought on maize yield and led Tumwesigye \& Musiitwa (2004) to characterize drought patterns to help in the development of drought resistant maize cultivars. The present study focuses on the severity and frequency of drought events in the Kenyan part of the LVB, with the hope of providing mitigation and/or adaptation measures necessary for key stakeholders to improve drought management.

\section{STUDY AREA AND DATA SOURCE}

The study area was centred on the Kenyan part of LVB, with data taken from Kisumu station, $0.1^{\circ} \mathrm{S}$, $34.75^{\circ} \mathrm{E}$ (Fig. 1). The station is approximately $1500 \mathrm{~m}$ above mean sea level. The region has 4 seasons: the hot dry season (December to February, DJF); the major rainy season (March to May, MAM); the short dry season (June to August, JJA); and the short rainy season (September to November, SON) (Awange \& Ong'ang'a 2006). Kisumu has an annual average rainfall of $1340 \mathrm{~mm}$, and experiences relatively high rainfall for the region (Amissah-Arthur 2002 found that both annual rainfall and rainfall during the long rainy season were greater at Kisumu than at any of the 8 stations in Kenya that they analysed). The highest rainfall in the LVB occurs in the north-western parts and gradually decreases towards the southeast. The average annual rainfall for the LVB is $1424 \mathrm{~mm}$ and varies between $891 \mathrm{~mm}$ in parts of Mara catchments to a maximum of $2168 \mathrm{~mm}$ in the middle of Yala Basin (APFM 2004).

The principal occupation in the LVB is subsistence agriculture (e.g. maize, sorghum, beans, cassava), and planting takes place largely during the long and short rainy seasons (February to March and September to October, respectively). This contrasts with the rest of Kenya, where planting generally occurs in March to April and October to November (Amissah-Arthur et al. 2002). Recently however, this pattern has changed. During the 2005 long dry spell, for example, the planting season started as late as April-May in most parts of LVB (Kenya), and in 2006 it started in late March in most places.

As a response to these changing patterns, farmers have intensified the planting of drought resistant crops (e.g. sweet potatoes and cassavas). Cassava crops are, however, in decline, as consumer preferences shift towards maize and rice; poor cassava yields are also attributed to destruction by moles (Kiptot et al. 2006). This further exacerbates food insecurity. Maize is the preferred crop, and (together with legumes) is often planted in both rainy seasons, due to the fact that one yield is often insufficient to sustain farmers through the year. In addition to the problem of drought, poor soil fertility resulting from a lack of crop rotation has also contributed to serious food insecurity in the region. To address these emerging threats of drought and soil infertility, research is being done on drought-resistant varieties of maize. 


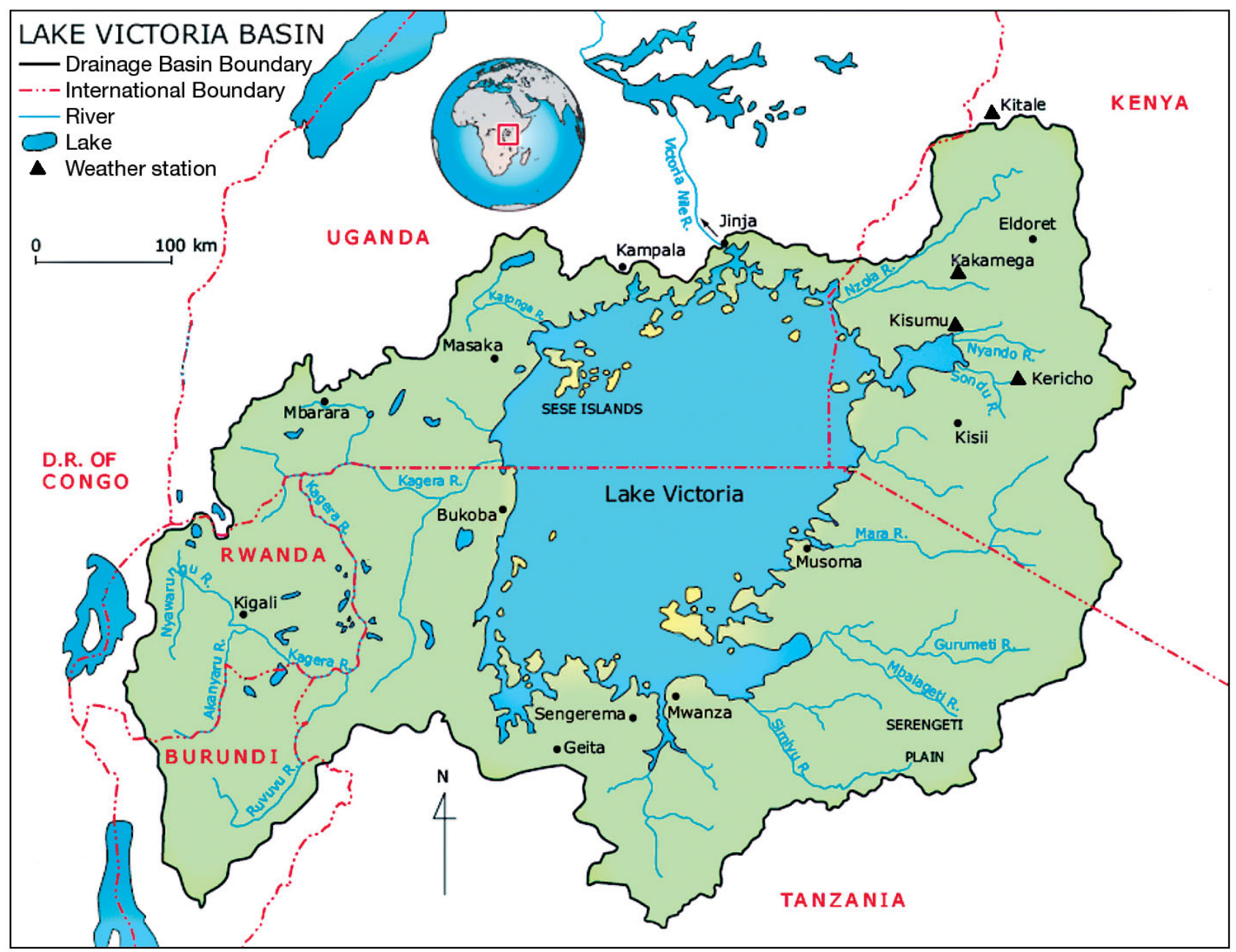

Fig. 1. Lake Victoria basin (from Kayombo \& Jorgensen 2006) and weather stations in the Kenyan part of the region

The data used in this study consisted of:

(1) Rainfall data (1961-1999). Kisumu station was selected because of its position vis-à-vis other stations in the region (see Fig. 1). There are a number of other meteorological stations in the LVB, but all are found in the same (Lake Victoria) climatological zone. We therefore used one station to represent the region in order to avoid duplication of results. Kisumu is very close to Lake Victoria, and thus can sufficiently account for both the catchment and over-lake rainfall. Rainfall anomaly data are presented in Appendix 1.

(2) Food import data (1961-2002). Secondary data on food imports was obtained from abstracts provided by the Central Bureau of Statistics (CBS) (available at the Kenyan Ministry of Agriculture's Library) and are presented in Appendix 2. Maize being the staple food in the region, the quantities of maize imports from 1961-2002 were used to represent overall food imports. In Kenya food is not normally imported for specific regions affected by drought; rather, the affected region triggers imports of food to the national reserve. When drought is severe in the LVB, for example, the Government checks the national reserve for surplus. If the food stored in the national reserve begins to decline, and the other regions are not in a position to supply the national reserve, then an order is made to import food.

\section{ANALYSIS}

For easier analysis and comparison purposes, both rainfall and food data were standardized. The daily records data were averaged to get the monthly mean

$$
\bar{x}=\frac{\sum d}{n}
$$

where $d$ is the daily measurements and $n$ number of days in the month. The monthly means were averaged for the 3 months in a season to obtain a seasonal mean. To get the annual means, the monthly means for all the 12 months of the year were averaged. 
3.1. Determination of drought years. Once the rainfall mean was computed, the 'percent of normal' (quartile) was calculated by dividing actual precipitation by normal precipitation-typically considered to be a 30 yr mean-and multiplying by $100 \%$ (Eq. 3). Usually time scales range from a single month, or a group of months representing a particular season, to an annual or water year. Normal precipitation for a specific location was considered to be $100 \%$. The normal precipitation $N$ was calculated by

$$
N=\frac{\sum\left(\overline{X_{A M}}\right)}{30}
$$

i.e. $30 \mathrm{yr}$ mean of a season, where $\overline{X_{A M}}$ is the annual mean. Percent of normal $P_{n}$ was then given by

$$
P_{n}=\left(\frac{A p}{N}\right) \times 100 \%
$$

where $A p$ is the actual precipitation. The Drought Severity Index (DSI) was then determined by considering as 'dry' all those observations $<25 \%$ (first quartile) of the ranked historical records, while those which are $>75 \%$ (fourth quartile) are considered 'wet'.

3.2. Standardization of data. In order to compare the data, the rainfall and food data were standardized using

$$
Z=\frac{X_{t}-\overline{X_{30}}}{\sigma}
$$

where $Z$ is the standardized value, $X_{t}$ the observed value at a particular time, $\overline{X_{30}}$ the $30 \mathrm{yr}$ mean for the parameter and $\sigma$ is the standard deviation. This gave the anomalies that were used for plotting the time series charts (see Appendix 1).

3.3. Data analysis methods. Anomalies of the parameters were used in the plotting for comparison between rainfall and food variables from the standardized values of $Z$ in Eq. (4). Time series and relational analysis were then performed. The data were sorted in descending order; $25 \%$ of the normal and below represented the 'lower threshold'. The threshold value was then plotted in the time series, identifying severe and extreme drought as the 2 main categories (Table 1). This method was used to determine the frequency, severity and duration of drought.

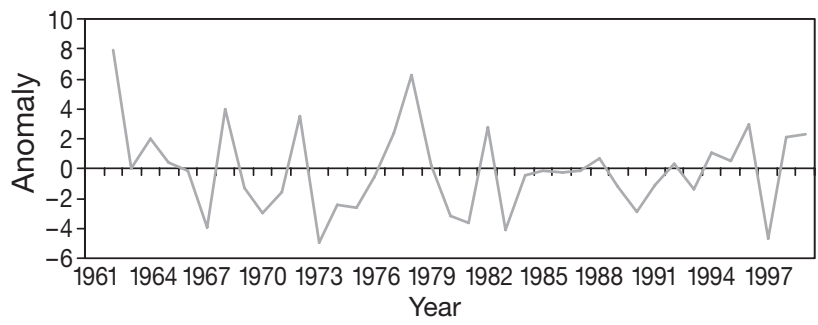

Fig. 2. Time series of annual rainfall anomalies at Kisumu during 1961-1999
Table 1. Percentage range for dry and wet spells

\begin{tabular}{|c|c|}
\hline Seasons & Drought years \\
\hline DJF & $\begin{array}{l}\text { 1967, 1971, 1974, 1975, 1981, 1982, 1983, 1984, } \\
\text { 1992, 1994, 1997, } 1999\end{array}$ \\
\hline MAM & $\begin{array}{l}\text { 1961, 1967, 1969, 1976, 1982, 1983, 1984, 1987, } \\
\text { 1992, } 1998\end{array}$ \\
\hline JJA & $\begin{array}{l}\text { 1963, 1965, 1967, 1969, 1970, 1973, 1980, 1989, } \\
\text { 1991, 1995, 1997, } 1998\end{array}$ \\
\hline $\mathrm{SON}$ & $\begin{array}{l}\text { 1963, 1966, 1970, 1973, 1975, 1977, 1980, 1981, } \\
\text { 1985, 1990, 1993, 1997, } 1998\end{array}$ \\
\hline
\end{tabular}

\begin{tabular}{|cl|}
\hline $\begin{array}{l}\text { Percentage rainfall } \\
\text { relative to mean }\end{array}$ & Physical conditions \\
\hline$>175$ & \\
$>150$ & Extremely wet \\
125 & Very wet \\
100 & Near normal \\
75 & Normal \\
$<50$ & Near normal \\
$<25$ & Severe drought \\
\hline
\end{tabular}

Table 2. Seasonal drought years

Table 3. Periods of drought and their intensity. Extreme: rainfall $<25 \%$ of normal; severe: $<50 \%$ to $25 \%$ of normal

\begin{tabular}{|ll|}
\hline Drought & \multicolumn{1}{c|}{ Year } \\
\hline Extreme & $1973-1975,1981-1985,1990-1993,1996-1997$ \\
Severe & $1963,1967,1970-1971,1980$ \\
\hline
\end{tabular}

\section{RESULTS}

4.1. Drought years. Fig. 2 indicates that the period from 1960 to 1970 was wetter with higher positive anomalies. The period 1970 to 1980 shows a mixed spell of wet and dry years, while 1983 to 1997 shows a largely dry spell with lower negative anomalies. Table 2 gives drought years obtained from observing the lower threshold values in Fig. 3, which were calculated as 1.2, 1.05, 0.98 and 1.38 for DJF, MAM, JJA and SON, respectively. Fig. 3 and Table 3 show the severity and duration of drought years. The worst drought in terms of severity was 1980-1985, and drought events have been increasing in recent years. Because of the El Niño rains of 1998, the 1990s were not particularly dry, but significant droughts did occur in 1990 and in 1997. A general pattern of drought emerges

- During the hot dry season (DJF), severe drought can be expected approximately every 7 to 8 yr

- During the long rainy season (MAM), severe drought can be expected every 5 to 8 yr 

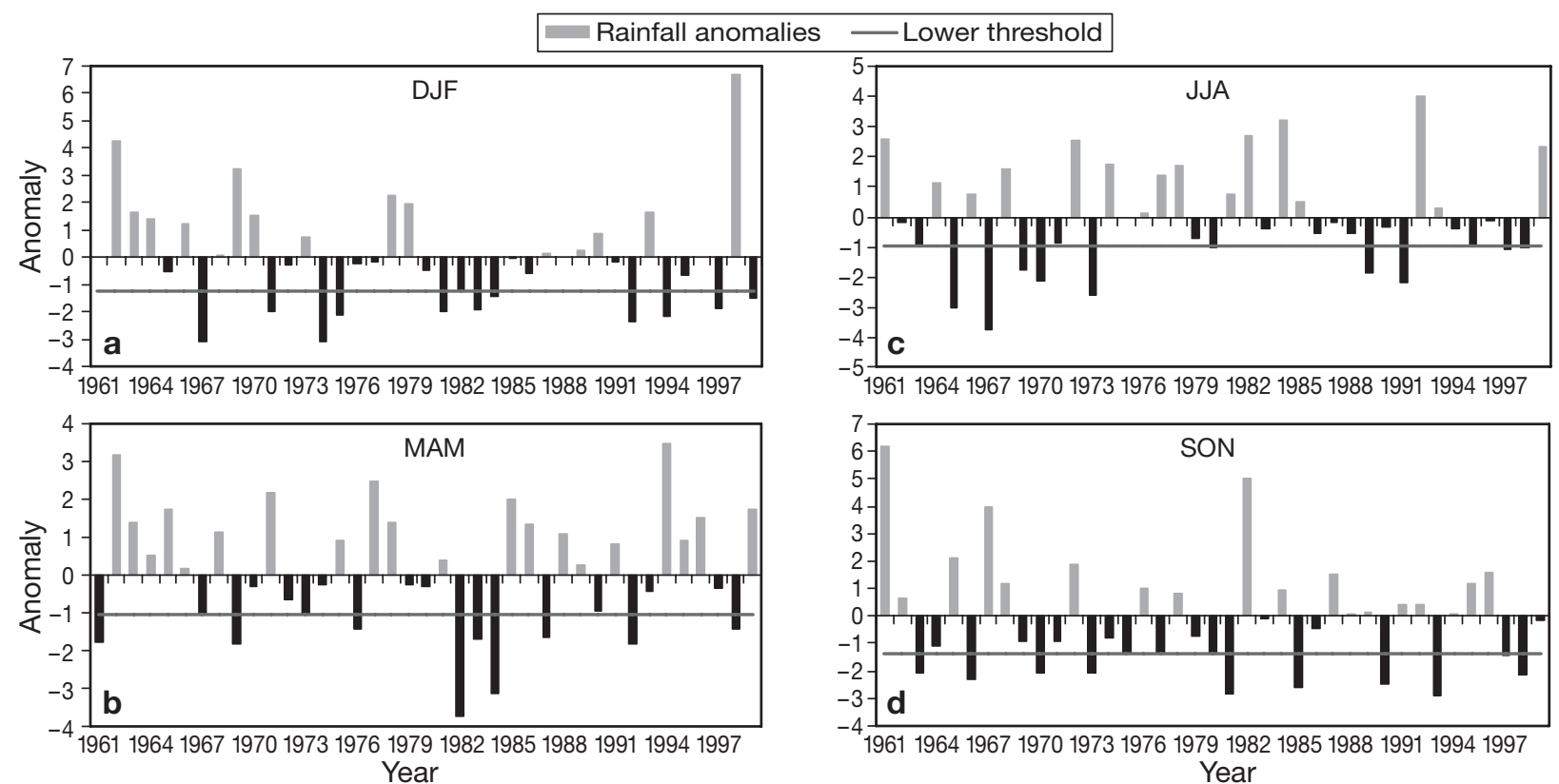

Fig. 3. Seasonal droughts from 1961-1999 (see Section 2 for season abbreviations)
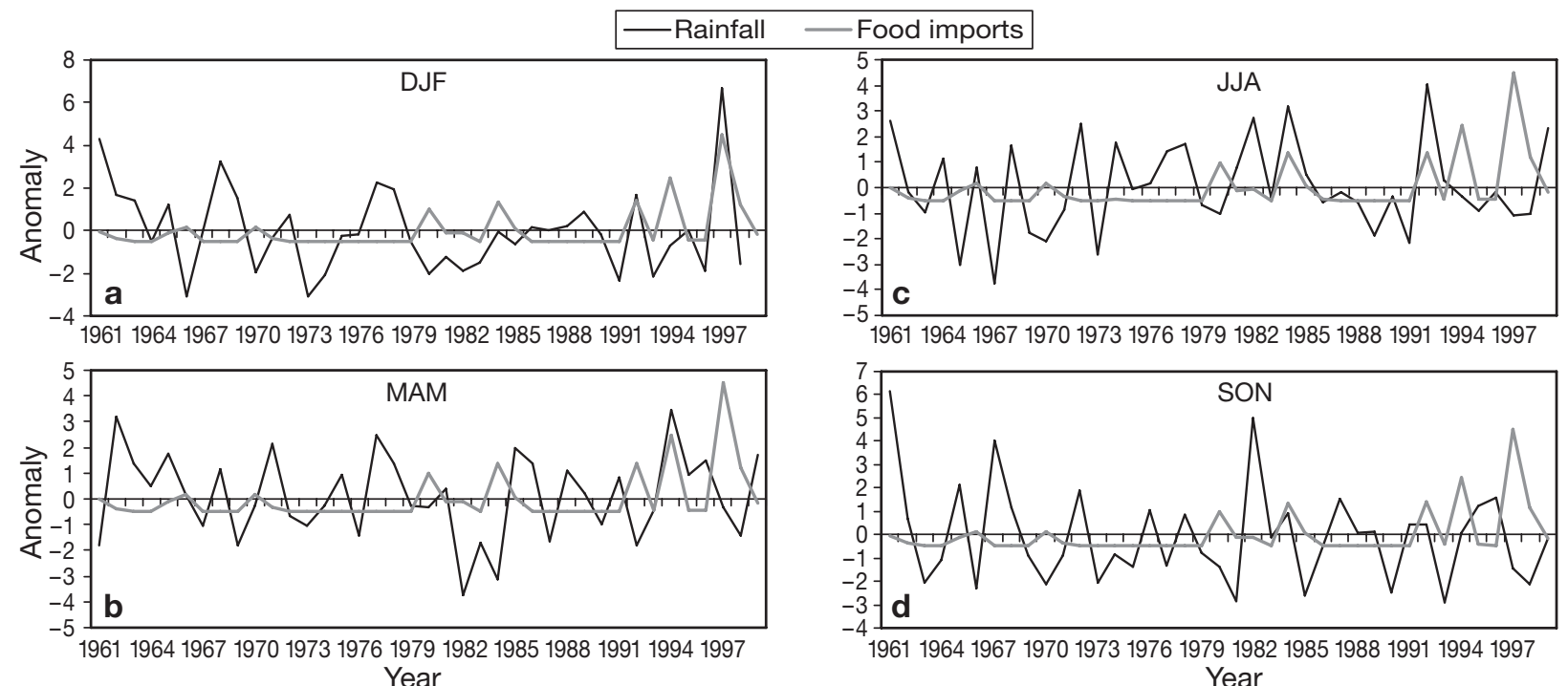

Fig. 4. Time series of food imports relative to the 4 seasons during 1961-1999

- During the dry season (JJA) there is no clear cycle of drought events

- During the short rainy season (SON), severe drought can be expected every 3 to 4 yr.

4.2. Drought in relation to food security. In the LVB the long and short rainy seasons (i.e. MAM and SON, respectively) are critical to food security. Fig. 4 shows the relationship between the various seasonal droughts and food imports. For all the seasons considered, there is a significant rise in food imports in the years 1966,
Table 4. Drought profile in relation to numbers of people receiving food relief in the Lake Victoria region of Kenya (all droughts were geographically widespread). Source: Kenya Government Disaster Preparedness Paper

\begin{tabular}{|lcc|}
\hline Year & Drought & No. of people \\
\hline $1983-1984$ & Extreme & 200000 \\
1980 & Severe & 40000 \\
1975 & Severe & 16000 \\
1971 & Extreme & 150000 \\
\hline
\end{tabular}




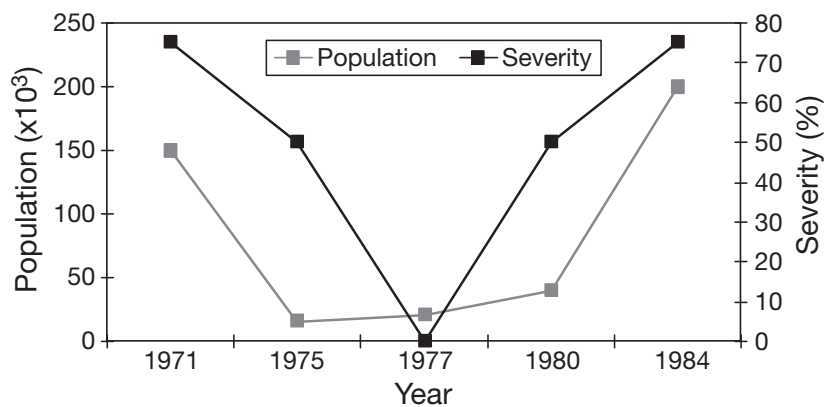

Fig. 5. Relationship between drought severity and foodinsecure population in Kenya

1970, 1980, 1984, 1992, 1994 and 1997. These years followed the drought years identified in Tables $2 \& 3$, with a lag of 1 yr. From the drought profile in Table 4, a relationship between drought severity and populations affected by food relief was established (Fig. 5), which indicates that as drought severity increases, population receiving food relief also increases, and it also shows that after a significant drop of drought severity from 1971 to 1975 , the population receiving food relief during this time also decreased.

\section{DISCUSSION}

The information on drought patterns in the LVB is vital to farmers' drought management planning, as well as to that of the Ministry of Agriculture and the National Disaster Management body.

The variability of rain influences not only drought but also food imports (Fig. 4), and droughts in the LVB probably contribute to national food imports. This can be analysed using MAM and SON data. Fig. 4b,d shows wet periods for both seasons, suggesting that the increase of the food imported in 1966 could have been triggered by droughts from other regions, with the Lake Victoria region unable to make up shortfalls in the national basket.

In 1969 and 1979, MAM and SON were dry (negative anomalies, Figs. 3 \& 4). This could have affected the planting of maize during February-March and August-September, leading to a food shortage that triggered the food imports of 1970 and 1980. The extreme drought for Kenya as a whole during 1981-1985 (Table 3) severely affected the planting season of MAM, and triggered the food imports of 1984. The 1992 increase in food imports could be attributed to droughts in other parts of the country, since the rainfall anomalies of 1991 indicate a wet season in the LVB for MAM and SON. Similar to the El Niño years of 1997, rainfall in 1994 was above normal, which could have led to crop failure due to floods.
The food imports of 1994 therefore could not be attributed to drought.

The LVB is dependent on national food reserves in years of drought (Fig. 5), while also exerting an influence over these reserves through its fluctuating level of food production. Drought therefore contributes to food insecurity, not only for the LVB, but for the entire country. This information should therefore help the planners and managers intensify agricultural activities in the region for better crop yield to ensure food security in the country.

For the LVB, farmers, policy makers and other stake holders should consider the following courses of action.

(1) Development of crop varieties that are higheryielding, nutritious, drought resistant, early-maturing, and disease and pest tolerant. For instance, the PIONEER and PANNAR maize types are capable of maturing within 3 months, even with low rainfall. The setback is that the crop is favoured by weevils, and significant losses could occur through lack of proper treatment (this is a particular danger where yields are large, since farmers may fail to treat the entire crop in an attempt to reduce treatment costs). Information on such types of seed needs to be disseminated to farmers and the seeds made accessible and affordable to them.

(2) The need to educate the people on the drought patterns ascertained in the present study, and the need to embrace drought resistant crops. For example, cassava - a favourite crop from the 1960s to the 1980s - is rapidly losing favour among farmers, because of its relatively poor performance in drought conditions and because of shifts in consumer preference.

(3) Research and development of improved technologies in agriculture; for example, irrigation, such as has been achieved by the Yala Swamp project (despite doubts that were initially expressed concerning its environmental consequences - mostly on wetlandssee Awange \& Ong'ang'a 2006).

(4) Studies to establish the stored water potential of LVB. This will assist in further studies on drought within the region.

\section{CONCLUSIONS}

Increased precipitation variability in the LVB has led to an increase in drought events in the recent past. Drought in the region is inversely related to food security (though the relationship is an indirect one), and if the current drought trend persists, it is likely to have further negative effects. In the past, negative effects of drought may have stemmed from an inability to anticipate and cope with drought events. However, severe climate extremes were not as frequent as in recent decades, and since the current trend of rainfall vari- 
ability is expected to increase, drought severity is likely to be of greater magnitude, and with with much greater extremes. The effect of future droughts on food security are thus likely to be severe, and the task of recovering from them costly, if communities in this region do not anticipate trends of increased drought severity, and if they fail to adopt coping strategies. Drought analysis is therefore vital for proper food management.

Acknowledgements. The authors are grateful to the IGAD Climate Prediction and Applications Centre (ICPAC) for granting the facilities and data used in the study. Special thanks go to Dr. G. Ouma of the University of Nairobi, and to Ms F. Wairimu and Mr. W. Gitau (ICPAC), who were instrumental in obtaining the data, climatic products and other resources that were used in this research. We are grateful to the Central Bureau of Statistics (Kenya) for providing data on food imports.

\section{LITERATURE CITED}

Adger WN, Huq S, Brown K, Conway D, Hulme M (2003) Adaptation to climate change in the developing world. Prog Dev Stud 3:179-195

Akong'a, JJ, Downing TE (1988) Small holder vulnerability and response to drought. In: Parry ML, Carter TR, Konjin NT (eds) The impact of climate variations on agriculture, Vol 2. Assessments in semi-arid regions. Kluwer, Dordrecht, p 221-247

Amissah-Arthur A, Jagtap S, Rosenzweig C (2002) Spatiotemporal effects of El Niño events on rainfall and maize yield in Kenya. Int J Climatol 22:1849-1860

APFM (Associate Programme on Flood Management) (2004) Strategy for flood management for Lake Victoria Basin, Kenya. Available at: www.apfm.info/pdf/strategy_kenya_ e.pdf

Aseto O, Ong'ang'a O, Awange JL (2003) Poverty reduction: a challange of Lake Victoria Basin (Kenya). African Herald Publishing House, Kendu Bay

Awange JL, Ong'ang'a O (2006) Lake Victoria: ecology, resources and environment. Springer-Verlag, Heidelberg

Barrett CB (2002) Food security and food assistance programs. In: Gardner B, Rausser G (eds) Handbook of agricultural economics, Vol. 2. Elsevier Science, Amsterdam, p 2103-2190

DMCN (Drought Monitoring Centre Nairobi) (2002) Factoring of weather and climate information and products into disaster management policy. A contribution to strategies for disaster reduction in Kenya. UNDP, Government of Kenya, and WMO, Nairobi
Downing TE, Kangethe W, Karnaw C (1989) Coping with drought in Kenya: national and local strategies. Lynne Rienner, Boulder, CO

Ehrlich PR, Ehrlich AH, Daily GC (1993) Food security, population and environment. Pop Dev Rev 19:1-32

Garcia R, Escudero J (1982) The constant catastrophe: malnutrition, famines and drought. Drought and man series, Vol. 2. IFIAS Project, Pergamon Press, New York

Glantz HM (1987) Drought and hunger in Africa: denying famine a future. Cambridge University Press, Cambridge

Kadomura H (1994) Climate changes, drought, desertification and land degradation in the Sudano-Sahelian region: a historic geographical perspective. In: Kadomura H (ed) Savannization process in tropical Africa. II. Country briefs. Tokyo Metropolitan University, p 203-228

Kayombo S, Jorgensen SE (2006) Lake Victoria: experience and lessons learned brief. International Lake Environment Committee, Lake Basin Management Initiative, Kusatsu, Japan. Available at: www.ilec.or.jp/eg/lbmi/reports/27 Lake_Victoria_27February2006.pdf

Kiptot E, Franzel S, Hebinck P, Richards P (2006) Sharing seed and knowledge: farmer to farmer dissemination of agroforestry technologies in western Kenya. Agrofor Syst 68:167-179

Nicholson SE (1998) Historical fluctuations of Lake Victoria and other lakes in the Northern Rift Valley of East Africa. In: JT Lehman (ed) Environmental change and response in East African lakes. Kluwer, Dordrecht, p 7-35

Otieno HO, Awange JL (2006) Energy resources in East Africa. Springer-Verlag, Heidelberg

Phoon SY, Shamseldin AY, Vairavamoorthy K (2004) Assessing impacts of climate change on Lake Victoria Basin, Africa: people-centred approaches to water and environmental sanitation. 30th Water Engineering and Development Centre (WEDC) Int Conf, Vientiane, Lao PDR, p 392-397

Scoones L, Chibudu C, Chikura S, Jeranyama P and 8 others (1996) Hazards and opportunities: farming livelihoods in dryland Africa. Lessons from Zimbabwe. Zed Books, London

Shipton P (1990) African famines and food insecurity: anthropological perspectives. Annu Rev Anthropol 19:353-394

Skees JR (2000) A role for capital markets in natural disasters: a piece of the food security puzzle. Food Pol 25:365-378

Swaminathan MS (2001) Food security and sustainable development. Curr Sci 81:948-954

Tumwesigye EK, Musiitwa F (2004) Characterizing drought patterns for appropriate development and transfer of drought resistant maize cultivars in Uganda. In: Fiesen DK, Palmer AFE (eds) Integrated approaches to higher maize productivity in the new millennium: Proc 7 th Eastern and Southern Africa Regional Maize Conf, 5-11 February 2002, Nairobi, Kenya. CIMMYT (International Maize and Wheat Improvement Center) and KARI (Kenya Agricultural Research Institute), Nairobi, p 260-262 
Appendix 1. Seasonal rainfall anomalies for the Kisumu meteorological station

\begin{tabular}{|c|c|c|c|c|}
\hline Year & DJF & MAM & JJA & SON \\
\hline 1961 & & -1.8 & 2.6 & 6.2 \\
\hline 1962 & 4.3 & 3.2 & -0.2 & 0.7 \\
\hline 1963 & 1.7 & 1.4 & -1.0 & -2.1 \\
\hline 1964 & 1.4 & 0.5 & 1.1 & -1.1 \\
\hline 1965 & -0.5 & 1.7 & -3.0 & 2.1 \\
\hline 1966 & 1.2 & 0.2 & 0.8 & -2.3 \\
\hline 1967 & -3.1 & -1.1 & -3.7 & 4.0 \\
\hline 1968 & 0.1 & 1.1 & 1.6 & 1.2 \\
\hline 1969 & 3.3 & -1.8 & -1.8 & -0.9 \\
\hline 1970 & 1.5 & -0.3 & -2.1 & -2.1 \\
\hline 1971 & -2.0 & 2.2 & -0.8 & -0.9 \\
\hline 1972 & -0.3 & -0.6 & 2.5 & 1.9 \\
\hline 1973 & 0.7 & -1.0 & -2.6 & -2.1 \\
\hline 1974 & -3.1 & -0.3 & 1.8 & -0.8 \\
\hline 1975 & -2.1 & 0.9 & 0.0 & -1.4 \\
\hline 1976 & -0.2 & -1.5 & 0.2 & 1.0 \\
\hline 1977 & -0.1 & 2.5 & 1.4 & -1.3 \\
\hline 1978 & 2.3 & 1.4 & 1.7 & 0.8 \\
\hline 1979 & 1.9 & -0.3 & -0.7 & -0.8 \\
\hline 1980 & -0.5 & -0.3 & -1.0 & -1.4 \\
\hline 1981 & -2.0 & 0.4 & 0.8 & -2.9 \\
\hline 1982 & -1.2 & -3.7 & 2.7 & 5.0 \\
\hline 1983 & -1.9 & -1.7 & -0.4 & -0.1 \\
\hline 1984 & -1.5 & -3.1 & 3.2 & 0.9 \\
\hline 1985 & -0.1 & 2.0 & 0.5 & -2.6 \\
\hline 1986 & -0.6 & 1.4 & -0.6 & -0.5 \\
\hline 1987 & 0.1 & -1.7 & -0.2 & 1.5 \\
\hline 1988 & 0.0 & 1.1 & -0.5 & 0.1 \\
\hline 1989 & 0.2 & 0.2 & -1.9 & 0.2 \\
\hline 1990 & 0.9 & -1.0 & -0.3 & -2.5 \\
\hline 1991 & -0.2 & 0.8 & -2.2 & 0.4 \\
\hline 1992 & -2.3 & -1.8 & 4.0 & 0.4 \\
\hline 1993 & 1.6 & -0.4 & 0.3 & -2.9 \\
\hline 1994 & -2.2 & 3.5 & -0.4 & 0.1 \\
\hline 1995 & -0.7 & 0.9 & -0.9 & 1.2 \\
\hline 1996 & 0.0 & 1.5 & -0.2 & 1.6 \\
\hline 1997 & -1.9 & -0.3 & -1.1 & -1.4 \\
\hline 1998 & 6.7 & -1.4 & -1.0 & -2.1 \\
\hline 1999 & -1.5 & 1.7 & 2.3 & -0.2 \\
\hline
\end{tabular}

Editorial responsibility: Daniel Scott, Waterloo, Ontario, Canada
Appendix 2. Food imports (t) in Kenya (Central Bureau of Statistics, Statistical Abstract, 2003. Extract on Net Imports, Principle Articles, Table 52b)

\begin{tabular}{|c|c|c|c|}
\hline Year & Maize & Wheat & Rice \\
\hline 1961 & 102130 & 13004 & 4037 \\
\hline 1962 & 25590 & 52470 & 4128 \\
\hline 1963 & 36 & 8523 & 4594 \\
\hline 1964 & 264 & 6 & 672 \\
\hline 1965 & 81452 & 5999 & 2096 \\
\hline 1966 & 143444 & 24965 & 2021 \\
\hline 1967 & 73 & 4512 & 207 \\
\hline 1968 & 39 & - & 2995 \\
\hline 1969 & 268 & 45 & 245 \\
\hline 1970 & 14334 & - & 1149 \\
\hline 1971 & 29077 & 13000 & 10203 \\
\hline 1972 & 104 & 64821 & 2150 \\
\hline 1973 & 82 & 77083 & 23 \\
\hline 1974 & 728 & 13744 & 1502 \\
\hline 1975 & 357 & 82917 & 4 \\
\hline 1976 & 32 & 50 & 10001 \\
\hline 1977 & 32 & 33 & 24 \\
\hline 1978 & 80 & 90888 & 11 \\
\hline 1979 & 18 & 21152 & 241 \\
\hline 1980 & 323873 & 48462 & 1239 \\
\hline 1981 & 77394 & 49239 & 4573 \\
\hline 1982 & 89056 & 139326 & 11880 \\
\hline 1983 & - & 81946 & 44768 \\
\hline 1984 & 405443 & 149906 & 507 \\
\hline 1985 & 125454 & 143793 & 562 \\
\hline 1986 & 700 & 115281 & 61745 \\
\hline 1987 & - & 217857 & 39129 \\
\hline 1988 & - & 75578 & 10000 \\
\hline 1989 & 2 & 123535 & 30006 \\
\hline 1990 & - & 322632 & 27983 \\
\hline 1991 & - & 242612 & 61163 \\
\hline 1992 & 414929 & 100808 & 58920 \\
\hline 1993 & 12874 & 314410 & 37150 \\
\hline 1994 & 650387 & 353076 & 93519 \\
\hline 1995 & 11965 & 249134 & 28177 \\
\hline 1996 & 6759 & 486917 & 39159 \\
\hline 1997 & 1101105 & 388138 & 62435 \\
\hline 1998 & 368761 & 478865 & 62893 \\
\hline 1999 & 75520 & 578543 & 53358 \\
\hline 2000 & 409416 & 636045 & 105803 \\
\hline 2001 & 308606 & 617542 & 172246 \\
\hline 2002 & 229288 & 515179 & 148705 \\
\hline
\end{tabular}

Submitted: July 14, 2006; Accepted: November 21, 2006 Proofs received from author(s): February 3, 2007 